\title{
Correspondence
}

\section{An Unidentified VLF Station}

Sir,-During a search of the VLF portion of the radio spectrum for transmitting stations which might serve as mission on $14.9 \mathrm{kHz}$ which presented some puzzling propagation effects.

Its origin is unknown, and we have been unable to identify the operating agency or the location of the transmitter itself.

We have plotted the diurnal phase variations of the transmitted frequency for about six months, and, by correlating this information with the sunrise and sunset terminators which produce the major phase variations, we have determined that the signals arrive from the direction of the Gulf of Alaska (about $30^{\circ}$ true). The great circle distance from Lower Hutt is indefinite, except that it is inore than 8,000 kilometres.

Variations of signal strength suggest that at least a portion of the path is subject to PCA events. 'The station cannot be in Europe or Africa, or its signals would bo received along the short great circle path, which can bo rearlily identified by moans of the sumrise-sunset phenomena.

There is some exidence that the frequency is controlled hy an oscillator which is corrected daily by reference to an atornic standard.

The station is using one of a group of six frequencies used by an unidentified agency during 1969 to transmit known Omega format, except that the pattern consisted of six intervals over 3.6 seconds, as against the Omega pattern of eight intervals over ten seconds.

$\mathrm{No}$ information on the transmission described, or its "narigational" predecessors, which ceased transmission in January 1970, has been noted in the technical or scientific press, and any information on the existing transmissions on $14.9 \mathrm{kHz}$ known to other scientific workers in this fiold would be welcomed by this laboratory.

\section{Yours faithfully,}

\section{C. Probine}

Thysics and Engineoring Laboratory,

DSIIR,

Privato Bag,

Lower Hutt,

New Zealand. sources of "whistler-mode" signals, we observed a transa repetitive sequence of short dashes, similar to the well

in terms of analytical formulae yielding quantitative results. (Topology) is of a more qualitative nature, offering newer concepts as the means of describing physical phenomena. . . . These concepts yield a fresh viewpoint and unifying relationships among apparently diverse structures". In typical metallurgical problems as complex as work-hardening, recrystallization, creep and the like, metallurgists have been so busy-and not very suceossfully as yet!--looking for analytical formulao that they have overlooked the possibility that perhaps topological relationships were more apt to answer their questions. I do not see any epistemological reason why nature must abhor topology. And in fact I would like to suggest that perhaps nature loves topology, as is shown by what I would call the "topological structure" of one of the most important relationships in physical chemistry, very well known, respected and used by all kinds of metallurgists: Gibbs's rule of phases.

Gibbs's rule possesses a striking similarity with Euler's theorem (which gave rise to the discipline of topology): If we call $V$ the number of vertices, $E$ the number of edgos and $F$ the number of faces of a polyhedron, then Fuler's theorem states that $V-E+F^{\prime}=2$. But if $Y$ is now the number of phases, $E$ the number of independent components and $F$ the number of degrees of freedom of a physico-chemical system, Gibbs's rule states that $T-E+$ $H=2$.

It can, of course, be said that this similarity is merely an accident, a formal curiosity without any furthor conse. quence, and that, besides, Gibbs's rule is not more than a useful "recipe", deduced from a system of analytical equations establishing the equilibrium conditions of a system of $V$ phases and $E$ components with $F$ degree of freedom. But the important thing to realize is not how the "recipe" is usually deduced, but its very nature: just as Euler's theorem makes possible a "goometry without metrics", Gibbs's rule permits one to analyse equilibrium without measuring anything. It provides a powerful means of dealing with the many variables of the equilibrium of any complex system. To evaluate how powerful it is, it is enough to try to imagine metallurgy without Gibbs's phase rule.

Are there many other topological relationships in the realm of metallurgy? According to Barrett and Yust, there are very few, and these do not seem to bo as important as Gibbs's phase rule. This paucity is not strange, bccause it seems that metallurgists have not been looking rery hard for applications of topology to their seience.

\section{Yours faithfully,}

\section{JORGE A. SABATO}

Departamonto de Metalurgia,

Comision National de Energia Atomica,

Buenos Aires, Argentina.

1 Barrett, L., and Xust, C., Metallography, 3, 1 (1970).

${ }^{2}$ Smith, C. S., Metel Interfaces (Amer. Society for Metals, Cleveland, 1952),

3 Smith C $\mathrm{S}$ A historical view of one area of applied sciences: metallurgy, Aplied Science and Technological Progress (National Acidlemy of Science, Aspa, 1967).

4 Cahn, R. W., Disconery, 41 (Juiy 1965).

1951 (ref. 2) on the analysis of grain shapes in a polycrvstal, only some 15 to 20 of the papers which have been published up to now on this problem, on tho sintering process and on the study of interfaces in a two-phase matorial, have applied topological theorems.

This lack of enthusiasm is really surprising because, by its very nature, topology seems to be a very appropriate trol to deal with metallurgy, a brand of scionce that proposes the "wary analysis of non-living complexity"3, "a perpetual balancing act between the realistic and the tractable". As Barrett and Yust put it: "Often mathematics. particularly applied mathematics, is thought of

\section{Abortion Act in Action}

SiR,-Since the publication of my letter on May 16 shown that abortion deaths in 1969 were in fuct a little up on 1967 , the last full year under the old law.

In Fngland and Wales, 10 deaths were dircetly attri(Nature, 226, 673;1970) more recent official figures ${ }^{1}$ have 